\title{
Plutonium and Americium Inventories in Soil Cores from the English Lake District, Cumbria (UK)
}

\author{
A. Madina ${ }^{1}$, C. Tighe ${ }^{1}$ and M. J. Joyce ${ }^{1}$ \\ ${ }^{1}$ Lancaster University, United Kingdom \\ m.joyce@lancaster.ac.uk
}

\begin{abstract}
Environmental radioactivity has been reported in the stationary wetlands closer to the natural water basins in Great Britain, precisely in the English Lake District (Cumbria, UK) often emphasise on the investigation carried out through either high-resolution $\gamma$-ray spectroscopy or $\alpha$ particle spectroscopy. The objective of the study is the evaluation of trace actinide $\left({ }^{241} \mathrm{Am}\right)$ through environments radioactivity measurements of two Lakes in the Lake District using a broad-energy, high-resolution $\gamma$-ray spectroscopy germanium (BEGe) detector. These appeal to the need to determine the radioactive concentration $(\mathrm{Bq} / \mathrm{g})$ in the soil samples with the intent being to discern natural and anthropogenic contributions, and trends in abundances associated with influences of the landscape over time, at trace levels in the environment. These measurements highlight potential benefits for the assessment of ${ }^{241} \mathrm{Am}$ and ${ }^{241} \mathrm{Pu}$, especially comparisons that might be made with accelerator mass spectrometry assessments (AMS). This study intents to offer an inclusive investigation practise for determining the levels of radioactivity in soil cores, as well as the method for statistical analysis approach to calculate the activity of a soil sample, with a special emphasis on categorising the natural and anthropogenic contributors to trace amounts of plutonium in the environment, that is, less than500 fg/g.
\end{abstract}

Keywords -Americium; plutonium; soil samples, radioactive concentration

\section{INTRODUCTION}

$\mathrm{T}^{\mathrm{s}}$ The Lake District is situated in the north of England in the United Kingdom; $\sim 4$ hours from London (see Fig. 1). It comprises an area of approximately $2,292 \mathrm{sq} . \mathrm{km}$, and is a UNESCO world heritage site [1] receiving around 18 million tourists every year under normal circumstances. As its name suggests, the Lake District comprises a significant number of land-locked lakes and water bodies. Many of these are relatively undisturbed and some of them have been subject to prior trace actinide analysis via high-resolution $\gamma$-spectroscopy and $\alpha$-particle assay in the past. The English Lake District offers a unique prospect to investigate the long-term dynamics of the long-term trace radioactivity in a natural environment that is relatively undisturbed, to inform studies of whether the majority of radioactivity arises naturally or, anthropogenically, from fallout from weapons tests and reactor accidents.

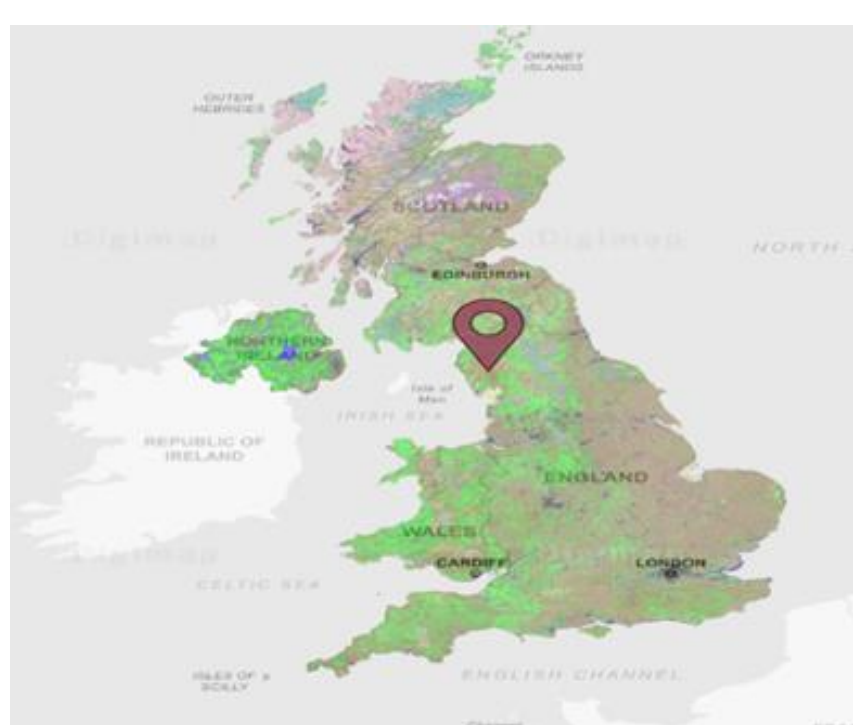

Fig. 1. The location of the Lake District in the United Kingdom

\section{DESCRIPTION}

Environmental radioactivity mensuration are essential to find the level of background radiation arising from natural radioactive sources (that include cosmic radiation originating in outer space and release through the atmosphere), and the terrestrial components arising from the radionuclides decays existing in rocks, water and sediments [2]. Furthermore to natural sources, the background radiation level encompasses man-made contributions such as those released from nuclear facilities such as Sellafield and other industrial sources [3].

The Lake District comprises uplands at elevations significant (maximum $978 \mathrm{~m}$ in height) relative to the surroundings and which are likely to have accumulated fallout from the Chernobyl accident in 1986 and atmospheric weapons tests. Sellafield is geographically close $(\sim 15 \mathrm{~km})$ and is the source of past radioactive effluent discharges to the environment (air, terrestrial and marine). It was also the site of the Windscale accident in 1957, which resulted in uncontrolled dispersion of radioactivity to the environment, mainly via airborne deposition.

The objective of the research described in this summary was to assess and compare trace quantities of plutonium and americium in soil cores collected from the shores of two specific sites in the Lake District (see: Fig. 2 and 3, Cumbria, 
UK): Blelham Tarn and Lake Windermere (at Fell Foot). For instance, this has been attempted by broad-energy germanium (BEGe), high-resolution $\gamma$-ray spectroscopy to determine the radioactivity concentration in the soil samples.

However, the established route to americium-241 assay, that is, via $\gamma$-ray spectroscopy of the ${ }^{241} \mathrm{Am}$ line at $59.5 \mathrm{keV}$, requires detailed analysis in a critical part of the $\gamma$-ray spectrum in terms of i) detector efficiency and ii) Compton background. This paper reports on the use of a BEGe detector to determine americium activity in soil samples from both sides Blelham Tarn and Fell Foot, Cumbria (UK).

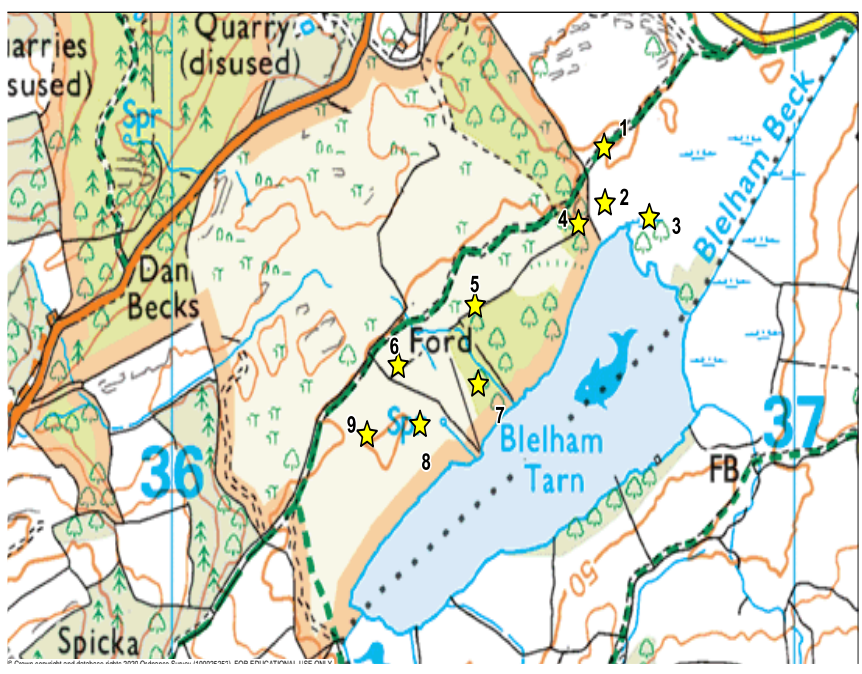

Fig. 2. The location (stars) of samples from the Blelham Tarn, Lake District (Cumbria, UK).

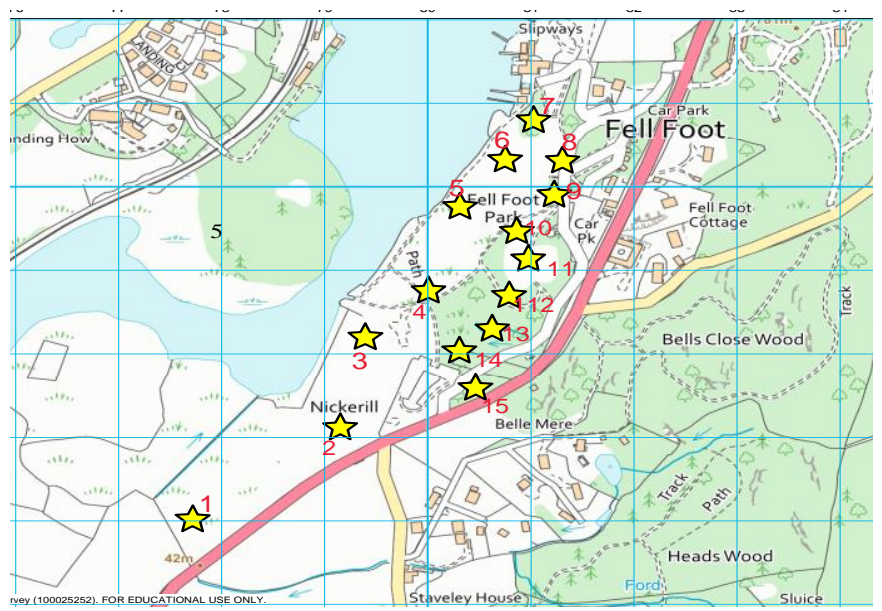

Fig. 3. The location (stars) of samples from Lake Windermere (Fell Foot Park) in the Lake District, (Cumbria UK).

\section{EXPERIMENTAL DETAILS}

The experimental methods used to detect natural and fallout radioactivities from Blelham Tarn and Lake Windermere soil samples were used to estimate radioactivity levels in other environmental samples using $\gamma$-ray spectrometers. This research was carried out at Central Teaching Laboratories (CTL Redaction Laboratory) at Liverpool University (UK), using a broad energy germanium (BEGe) counter (MIRON Technologies).
In this research program, a number of samples have been sourced from the environs of two sites in the Lake District to compare hydrogeological migration of trace actinide material: Blelham Tarn $\left(54.3966^{\circ} \mathrm{N}, 2.9766^{\circ} \mathrm{S}\right)$ which was studied 20 years ago [3], and constitutes a relatively undisturbed environment (that is, not used by boats or machines) and is also a site of special scientific interest (SSSI) which provides some guarantee to our assumed lack of disturbance [4].

Nine soil samples from Blelham Tarn and fifteen soil samples from Lake Windermere have been sourced, the latter from the northern shore, in this research (see: Figs. 2 and 3) with an aluminum, 50-mm diameter soil core sampler (see: Fig. 4). These samples were dried at $100^{\circ} \mathrm{C}$ for $24 \mathrm{hrs}$ to remove all impurities (that is, roots and stones) from samples and milled to grind soil in powder form. In addition, their locations were recorded with GPS, selected to correlate with the prior art [5] as closely as practicable and assessed in a BEGe $\gamma$-ray spectrometer to estimate the activity of ${ }^{241} \mathrm{Am}$ in each sample; the acquisition live time for each sample were 24 hours.

These data can be used to infer the ${ }^{241} \mathrm{Pu}$ activity based on a number of lifetime scenarios, ahead of accelerator mass spectrometry assessment (AMS) [6, 7] of the neighboring $\mathrm{Pu}$ activities and isotope ratios, scheduled later in this research program.

\section{RESULTS}

In Fig.5, an example BEGe spectrum for a sample studied in this research with the ${ }^{241} \mathrm{Am}$ peak highlighted and seen adjacent to the more intense lines derived from, for examples, the uranium and thorium decay chains that occur naturally.

In Fig 6, a graph is provided for a $\gamma$-ray spectrometry measurements of ${ }^{241} \mathrm{Am}$ from Blelham Tarn samples. Combining results from the soil core with data from the literature, the best estimate of ${ }^{241} \mathrm{Am}$ in-growth from ${ }^{241} \mathrm{Pu}$ decay is $41 \pm 5\left(\mathrm{~Bq} / \mathrm{m}^{2}\right)$ for sample 6 in Fig. 4 , if we compare that with Michel et al. [3], they find just $18 \pm 2\left(\mathrm{~Bq} / \mathrm{m}^{2}\right)$ at Blelham Tarn. For data for Blelham Tarn, measurements are presented in Table 1.

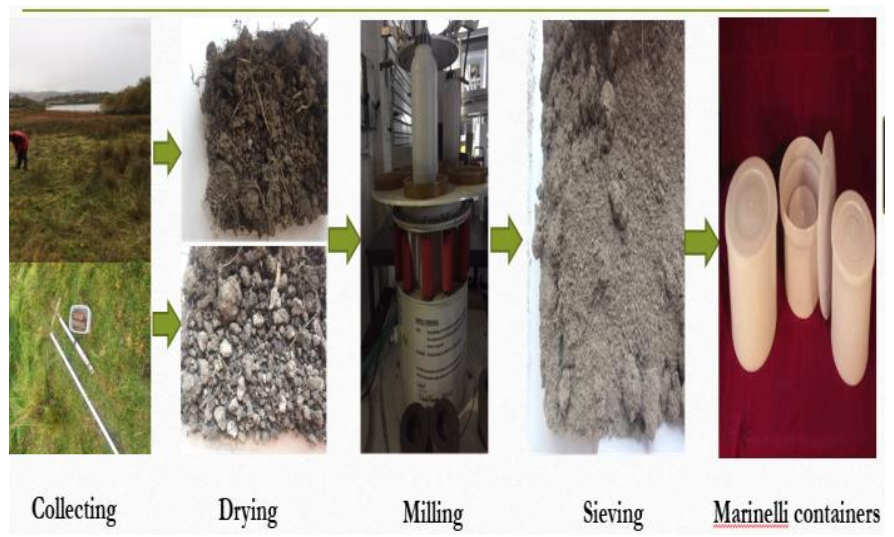

Fig. 4. The sample preparation strategy is illustrated in pictures adopted in this research, from left to right.

In Fig. 7, a similar graph is derived for a $\gamma$-ray spectrometry measurements of ${ }^{241} \mathrm{Am}$ for Lake Windermere, the mean of activity concentration of fifteen soil cores $(\mathrm{Bq} / \mathrm{g})$ of ${ }^{241} \mathrm{Am}$ was $(1.57 \pm 0.03) \times 10^{-4}$, where the life time was 24 hours and weight 
of each sample was $250 \mathrm{~g}$ for the measurement of mass concentration /g in this lake. For data for Lake Windermere, measurements are present in table 2.

From these results, the activity of ${ }^{241} \mathrm{Pu}$ can be estimated from the abundance of ${ }^{241} \mathrm{Am}$ based on an estimate of 30 years where the global deposition has occurred from, for example, weapons fallout and Chernobyl [8], using the Bateman equation [9]:

$$
A_{P u}(0)=\frac{A_{A m}(t)\left(\lambda_{A m}-\lambda_{P u}\right)}{\left(e^{-\lambda_{P u} t}-e^{-\lambda_{A m}}\right) \lambda_{A m}},
$$

where $A_{P u}$ and $A_{A m}$ are the activities of plutonium-241 and americium-241, respectively, and $\lambda_{P u}$ and $\lambda_{A m}$ are the corresponding decay constants.

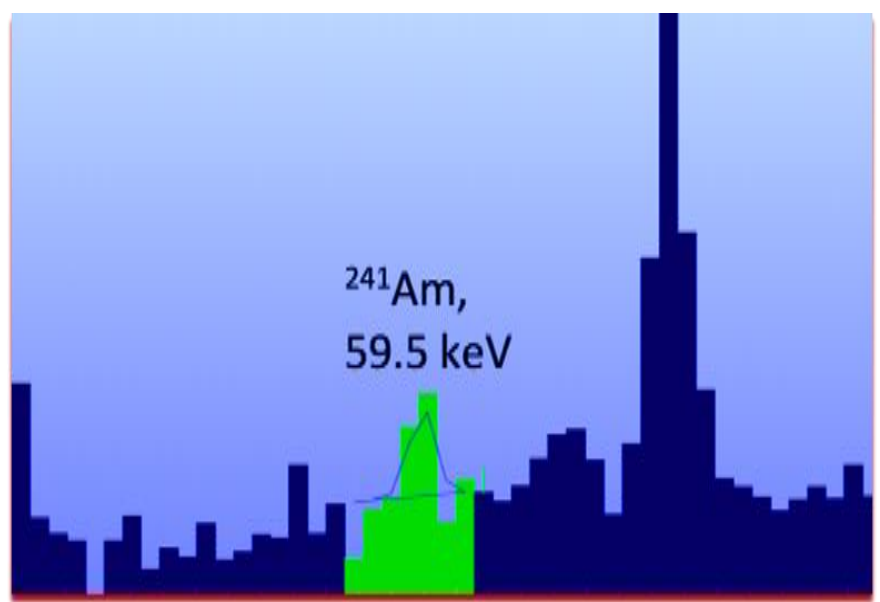

Fig. 5. A section of a BEGe $\gamma$-ray spectrum of soil sample \#2 in Blelham Tarn site.

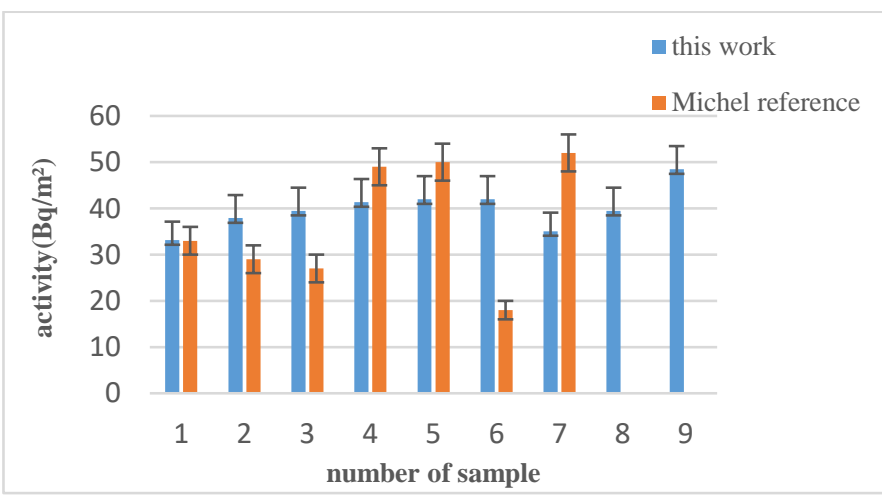

Fig. 6. Comparison of ${ }^{241} \mathrm{Am}$ activity $\left(\mathrm{Bq} / \mathrm{m}^{2}\right)^{241} \mathrm{Am}$ with that from Michel $e t$ al. [3] from Blelham Tarn, Like District (Cumbria, UK)

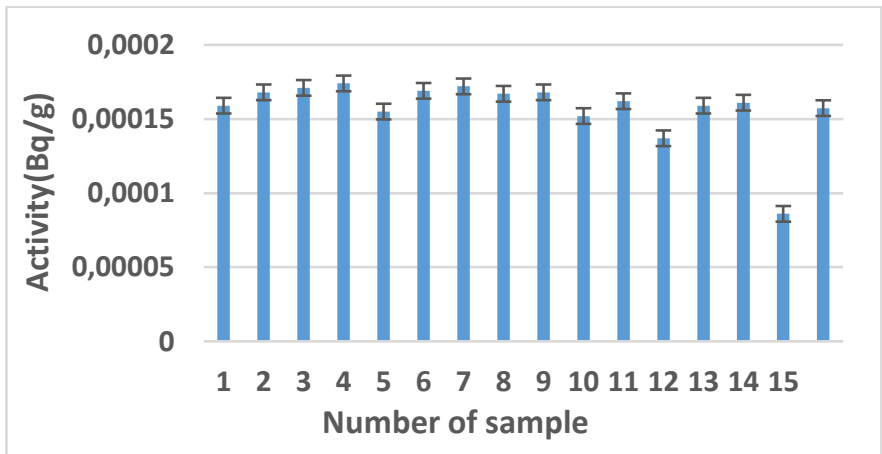

Fig. 7. Activity of ${ }^{241} \mathrm{Am}(\mathrm{Bq} / \mathrm{g})$ from Lake Windermere (Fell Foot Park), Lake District (Cumbria, UK).
TABLE I

${ }^{241} \mathrm{AM}$ ACTIVITY IN SOIL CORES FROM BLELHAM TARN

core $\quad$ Activity $\left(\mathrm{Bq} \mathrm{m}^{-2}\right)$

\begin{tabular}{ll}
\hline 1 & $33 \pm 4$ \\
2 & $38 \pm 5$ \\
3 & $39 \pm 5$ \\
4 & $41 \pm 5$ \\
5 & $42 \pm 5$ \\
6 & $42 \pm 5$ \\
7 & $25 \pm 4$ \\
8 & $39 \pm 5$ \\
9 & $48 \pm 5$ \\
means & $39 \pm 5$
\end{tabular}

TABLE II

${ }^{241}$ AM ACTIVITY IN SOIL CORES FROM LAKE WINDERMERE

core Activity $\left(\times 10^{-4} \mathrm{~Bq} / \mathrm{g}\right)$

\begin{tabular}{cc}
\hline 1 & $1.60 \pm 0.03$ \\
2 & $1.69 \pm 0.03$ \\
3 & $1.71 \pm 0.03$ \\
4 & $1.75 \pm 0.03$ \\
5 & $1.55 \pm 0.03$ \\
6 & $1.69 \pm 0.03$ \\
7 & $1.72 \pm 0.03$ \\
8 & $1.68 \pm 0.03$ \\
9 & $1.68 \pm 0.03$ \\
10 & $1.52 \pm 0.03$ \\
11 & $1.62 \pm 0.03$ \\
12 & $1.37 \pm 0.03$ \\
13 & $1.60 \pm 0.03$ \\
14 & $1.61 \pm 0.03$ \\
15 & $0.86 \pm 0.03$ \\
means & $1.57 \pm 0.03$
\end{tabular}

\section{CONCLUSIONS}

This research indicates that this approach could benefit related radioanalytical methods for ${ }^{241} \mathrm{Am}$ based on the 59.5 $\mathrm{keV} \gamma$-ray line, and hence assay of ${ }^{241} \mathrm{Pu}$, especially since AMS measurements are generally more sophisticated and destructive assessments than BEGe, and can be limited in discerning ${ }^{241} \mathrm{Am}$ and ${ }^{241} \mathrm{Pu}$ from one another because of their closely-lying isobars.

\section{ACKNOWLEDGMENTS}

The authors would like to express their gratitude to the Royal Society, for a Wolfson Research Merit Award (M. J. J.), the UK National Trust and Lancaster University for funding A. M.'s PhD studentship.

\section{REFERENCES}

[1] BBC News, $9^{\text {th }}$ July 2017, 'UNESCO awards Lake District World Heritage site status', https://www.bbc.co.uk/news/ukengland-cumbria-40547691

[2] Q. M.R. Nizam et al., 'Assessment of activity concentrations of Radionuclides from Upper Level Sediment in Charfassion', Nuclear and Particle Physics 3(3):36-39 (2013).

[3] H. Michel et al., 'Plutonium, americium and cesium records in sediment cores from Blelham Tarn, Cumbria (UK)', J. Radio. Nucl. Chem. 247 (1) pp. 107-110 (2001).

[4] http://www.environmentlaw.org.uk/rte.asp?id=303. 
[5] H. Michel et al., 'Plutonium and americium inventories in atmospheric fallout and sediment cores from Blelham Tarn, Cumbria (UK), J. Envir. Radio. 59 pp.127-137 (2002).

[6] M. J. Joyce et al. 'Searching for zero plutonium in the far north of Scotland', Actinide Research Quarterly, (2) pp. 27 (2019).

[7] M. J. Joyce et al. 'A comparison of plutonium abundance in soil from sites in the United Kingdom measured with highefficiency, high-resolution $\gamma$-ray spectroscopy, neutron assay and accelerator mass spectrometry', Plutonium Futures 2018, San Diego, September 2018.

[8] M. J. Joyce et al. 'A Comparison of $\gamma$-ray spectroscopy with Accelerator Mass Spectrometry for environmental assay of plutonium', EEE Nuclear Science Symposium and Medical Imaging Conference Proceedings (NSS/MIC), 2018, pp. 1-3, doi: 10.1109/NSSMIC.2018.8824687.

[9] M.J. Joyce 'Nuclear Engineering: A Conceptual Introduction to Nuclear Power'. Netherlands: Elsevier Science, 2017, pp.56-57. 